\title{
Early stages of implantation as revealed by an in vitro model
}

\author{
H Singh $^{1}$, L Nardo ${ }^{1}$, S J Kimber ${ }^{2}$ and J D Aplin ${ }^{1}$ \\ ${ }^{1}$ Maternal and Fetal Health Research, Manchester Academic Health Sciences Centre and ${ }^{2}$ Faculty of Life Sciences, \\ St Mary's Hospital, University of Manchester, 5th Floor Research, Manchester, M13 9WL, UK
}

Correspondence should be addressed to J D Aplin; Email: john.aplin@manchester.ac.uk

\begin{abstract}
Our limited understanding of the processes underlying steroid hormonal control of human endometrial receptivity is largely due to the lack of a relevant model system. To overcome scarcity of material, we have developed a model in which mouse embryos attach to human Ishikawa cells, which express functional steroid hormone receptors. Blastocysts flushed from day 4 pregnant superovulated mice were transferred to confluent Ishikawa cell monolayers. After $48 \mathrm{~h}$ of co-culture, $85 \%$ of the blastocysts had attached loosely, but only $40 \%$ attached stably to the epithelial cell surface. In contrast, $95 \%$ of the embryos attached stably to tissue culture plastic. Thus, weak attachment of a majority of the embryos was followed by stronger adhesion of a smaller proportion. Seventeen percent of the transferred blastocysts modified the epithelial cell surface with loss of MUC1 at the attachment site, extending variably to adjacent epithelial cells. Initially, stable attachment occurred without disruption to the integrity of the epithelial monolayer, but at later stages after the embryo had spread laterally, displacement of subjacent cells was observed. A modest increase in stable attachment, but no changes to MUC1 clearance, was observed after assisted hatching. After $24 \mathrm{~h}$ priming of Ishikawa cells by $17 \beta-o e s t r a d i o l ~\left(O E_{2}\right)$ followed by 72-h incubation with medroxyprogesterone acetate and $\mathrm{OE}_{2}$, stable attachment increased from 40 to $70 \%$. Initial attachment is efficient either in the presence or in the absence of hormone; steroid treatment increased the incidence of stable attachment. Implantation failure is predicted to occur in this model when embryos fail to progress from initial to stable attachment.

Reproduction (2010) 139 905-914
\end{abstract}

\section{Introduction}

Implantation involves a succession of genetic and cellular signals (Lessey 2002, Aplin \& Kimber 2004) that implement a reciprocal interaction mediating apposition and adhesion between trophectoderm in the blastocyst and uterine epithelium, followed by trophoblast invasion (Aplin 2006). In the mid-secretory phase of the menstrual cycle, there is a period of receptivity when the embryo can implant (Bergh \& Navot 1992, Aplin \& Kimber 2004). In both humans and mice, the apposition and adhesion stages are of short duration (Psychoyos 1986, Bergh \& Navot 1992, Lopata 1996, Aplin 2000), and both observational and experimental studies have been limited by this constraint. Despite advances in assisted reproductive technology (ART), only $20-25 \%$ of the treatment cycles result in a live birth (de los Santos et al. 2003). Unravelling the signals that pass between embryo and maternal cells will suggest strategies to reduce implantation failure and increase clinical pregnancy rates in women undergoing ART.

Attachment initially involves the external cell surfaces of trophectoderm and uterine epithelial cells over which a glycocalyx is present (Aplin et al. 1996, 1997) containing mucins (Ligtenberg et al. 1992), which contribute significantly to the anti-adhesive nature of the apical epithelial surface (Devine \& McKenzie 1992, Hilkens et al. 1992, Wesseling et al. 1996, Lagow et al. 1999). Significant upregulation of the transmembrane mucin MUC1 (Hey et al. 1994, 1995, Aplin et al. 1996, 1998, Meseguer et al. 2001) and its associated glycans keratan sulphate (Hoadley et al. 1990, Aplin et al. 1998), sialyl lewis x (Hey \& Aplin 1996) and Dolichos biflorus agglutinin (DBA)-binding ligands (Aplin 1991, Jones et al. 1998, Campbell et al. 2000) occurs during the secretory phase of the menstrual cycle, and might play a role in mediating the initial embryo-uterine epithelial interaction. During embryo attachment, the glycocalyx is reduced in thickness by a locally acting mechanism (Thathiah \& Carson 2004, Horne et al. 2005). The human blastocyst modifies the glycocalyx of endometrial epithelial cells in co-culture with local loss of MUC1 (Meseguer et al. 2001). The molecular mechanism of this phenomenon remains unknown, though selectin-ligand binding has been suggested as one component of the cascade (Genbacev et al. 2003). In mice, although MUC1 protein is highly expressed in the luminal and glandular epithelial cells of the uterus in pro-estrous, estrous and metaestrous, at d3 of pregnancy, it decreases in the luminal epithelium, apparently under maternal control, and by $\mathrm{d} 4$, it is almost completely lost in both luminal and glandular epithelium (Surveyor et al. 1995). 
In humans, the blastocyst adhesion stage is of short duration, limiting studies in vivo. While in vitro studies cannot completely mimic the intrauterine environment, they can model some of the potential interactions (Meseguer et al. 2001) and provide a framework within which molecular parameters may be manipulated. Ethical issues and availability limit the use of human embryos and implantation stage endometrial tissue. So, we have turned to Ishikawa, an endometrial epithelial cell line showing moderate apical-basal polarity (Hohn et al. 2000, Heneweer et al. 2005), steroid hormone receptors (Nishida et al. 1985, Hata \& Kuramoto 1992, Lessey et al. 1996, Mo et al. 2006, Uchida et al. 2007) and cell adhesion molecules (Castelbaum et al. 1997, Somkuti et al. 1997, Widra et al. 1997), which have been implicated in implantation (Sutherland et al. 1993). Although specific mechanics and cellular architecture of implantation vary among species, implantation in mice occurs at a defined window of uterine receptivity (Psychoyos 1986, Yoshinaga 1988), and a reciprocal interaction between the blastocyst and luminal epithelium is essential, leading to interstitial penetration of trophoblast, as in humans. Thus, for modelling implantation in vitro, use of mouse blastocysts seemed appropriate to overcome scarcity of human embryos.

We hypothesised that mouse embryos would attach to human endometrial epithelial cell monolayers, that this process might be sensitive to an assisted hatching protocol and to steroidal stimulation, and that attachment might lead to altered mucin distribution at the apical epithelial surface. The observations have led us to formulate new hypotheses regarding the early phases of implantation in humans in vivo.

\section{Results}

\section{Attachment of mouse blastocysts to Ishikawa cells}

In each experiment, embryos from several mice were pooled and randomly allocated to microwells containing confluent Ishikawa cells. In the initial experiment, 21 embryos were transferred and co-cultured for $48 \mathrm{~h}$. Only $10 \%$ of the transferred embryos had attached to the cells when the plate was examined at $24 \mathrm{~h}$. At $48 \mathrm{~h}$ of undisturbed co-culture, an increase in the number of attached embryos was observed compared with $24 \mathrm{~h}$ incubation. Leaving the co-culture for $72 \mathrm{~h}$ did not lead to any further increase compared with attachment at $48 \mathrm{~h}$ incubation. Hence, in later experiments, we incubated blastocysts with Ishikawa cell monolayers without observation for $48 \mathrm{~h}$ to gather data on embryo attachment.

The results presented are the outcome of 18 experiments (Table 1, row 1 ) that were performed to examine attachment of zona-intact blastocysts naturally hatching in co-culture at $48 \mathrm{~h}$. Subsets of these experiments were used in further analysis for MUC1 clearance/glycocalyx modification, also shown in Table 1. Overall attachment rates are based on mean percentage from each experiment \pm S.E.M. Blastocysts attached loosely (attachment 1 ) to the cell monolayer at a high rate (85\%). Embryos that remained attached after fixation were defined as having attached stably (attachment 2). Of the total transferred embryos, significantly fewer embryos $(38 \% ; P<0.001)$ reached this stage. Attachment sites that were visualised under the phase contrast microscope displayed a complete cell monolayer beneath and adjacent to the embryo attachment site (Fig. 1). Confocal optical sections of stably attached

Table 1 Summary of embryo attachment data.

\begin{tabular}{|c|c|c|c|c|c|}
\hline Cell/embryo treatment & $n$ & $N$ & Attachment 1(\%) & Attachment 2(\%) & Clearance \\
\hline $\begin{array}{l}\text { Control cells and naturally hatched embryos: } \\
\text { overall total }\end{array}$ & 351 & 18 & $84.7 \pm 4.6$ & $38.4^{\mathrm{a}} \pm 3.3(P<0.001)$ & \\
\hline $\begin{array}{l}\text { Control cells and naturally hatched embryos - } \\
\text { MUC1 clearance studies (subset of } 351 \text { embryos) }\end{array}$ & 154 & 12 & $88.8 \pm 4.8$ & $40.0^{\mathrm{a}} \pm 5.8(P<0.001)$ & $16.9^{\mathrm{b}} \pm 4.4(P<0.05)$ \\
\hline $\begin{array}{l}\text { Control cells on plastic substrate and naturally } \\
\text { hatched embryos }\end{array}$ & 48 & 8 & $98.9 \pm 1.1$ & $41.3 \pm 9.9$ & \\
\hline $\begin{array}{l}\text { Control cells on glass substrate and naturally } \\
\text { hatched embryos }\end{array}$ & 62 & 8 & 0 & 0 & \\
\hline Controls cells and naturally hatched embryos & 99 & 3 & $94.0 \pm 3.8$ & $32.8^{\mathrm{a}} \pm 5.1(P<0.001)$ & \\
\hline Control cells and assisted hatched embryos (AH) & 63 & 3 & $93.6 \pm 4.5$ & $53.0^{\mathrm{C}} \pm 7.5(P<0.05)$ & \\
\hline $\begin{array}{l}\text { Control cells and naturally hatched embryos - for } \\
\text { MUC1 clearance (subset from } 99 \text { embryos) }\end{array}$ & 49 & 3 & $94.0 \pm 3.9$ & $29.2^{\mathrm{a}} \pm 7.7(P<0.001)$ & $11.0^{\mathrm{b}} \pm 7.4$ \\
\hline $\begin{array}{l}\text { Control cells and assisted hatched embryos - for } \\
\text { MUC1 clearance (subset from } 63 \text { embryos) }\end{array}$ & 33 & 3 & $100.00 \%$ & $57.5 \pm 12.3$ & $12.5^{\mathrm{d}} \pm 7.2(\mathrm{NS})$ \\
\hline $\begin{array}{l}\text { Control cells and naturally hatching embryos - for } \\
\text { steroid studies }\end{array}$ & 48 & 4 & $96.9 \pm 1.8$ & $43.3^{\mathrm{a}} \pm 5.5(P<0.001)$ & \\
\hline $\begin{array}{l}\mathrm{OE}_{2}+\text { MPA-treated cells and naturally hatching } \\
\text { embryos - for steroid studies }\end{array}$ & 51 & 4 & $98.5 \pm 1.5$ & $70.3^{\mathrm{e}} \pm 5.7(P<0.01)$ & \\
\hline
\end{tabular}

Statistical comparisons were made as appropriate by one-way ANOVA or Tukey's multiple comparison on arcsine log-transformed data. NS, not significant.

${ }^{\mathrm{a} A t t a c h m e n t} 2$ versus attachment 1. ${ }^{\mathrm{b}}$ Clearance versus attachment 2. ${ }^{\mathrm{c} A t t a c h m e n t} 2$ in assisted hatching versus attachment 2 in control embryos.

${ }^{\mathrm{d}}$ Clearance by assisted hatching embryos versus clearance in normally hatched embryos. ${ }^{\text {eAttachment }} 2$ in steroid-treated cultures versus untreated controls. 


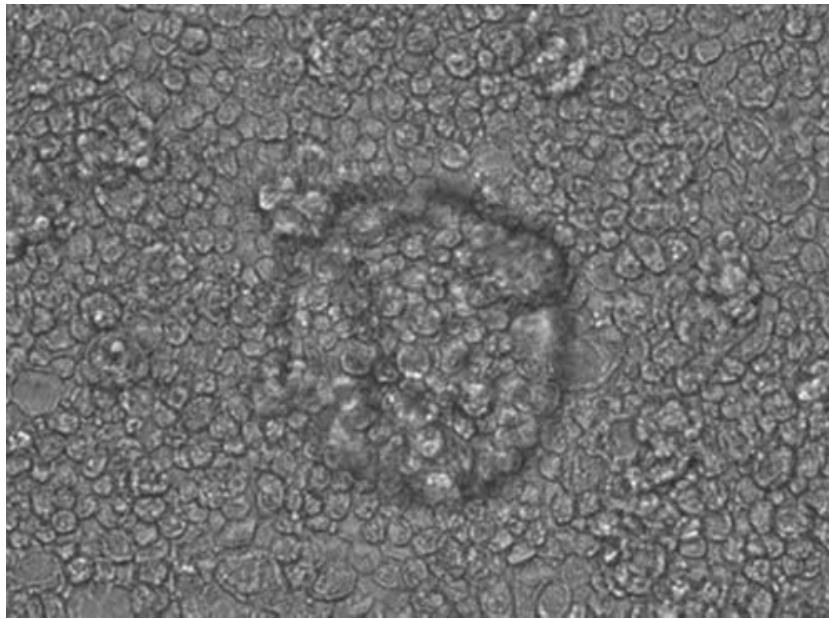

Figure 1 Mouse blastocyst attached to Ishikawa cells. Phase contrast image of a mouse blastocyst stably attached to Ishikawa cells in a 96-well microplate after $48 \mathrm{~h}$ of co-culture. The embryo is retained at its original location after paraformaldehyde fixation, with trophectoderm layer intact. $20 \times$ magnification.

blastocysts indicated that stable attachment can occur with minimal or no disruption to the underlying epithelial cell layer. However, when stably attached embryos had begun to spread laterally, displacement or disruption was observed in the epithelial layer subjacent to the attachment site (Fig. 2).

In an attempt to carry out optimal high resolution light microscopic morphological studies and to compare the rates of attachment, Ishikawa cells were grown on culture-grade glass chamber well slides or coverslips as well as on tissue culture-grade plastic. Embryos completely failed to attach on cells grown on glass $(P<0.001)$ compared with cells grown on plastic (Table 1, row 4). As a control, all the transferred blastocysts attached and outgrew efficiently on plastic, while $\sim 60 \%$ of the transferred embryos attached directly on the glass substrate.

\section{Clearance of MUC1 from Ishikawa cells occurs after attachment of the mouse blastocyst}

Ishikawa cells express MUC1 and associated glycans as a mosaic of varying intensity (Fig. 3A), and their apically specific expression acts as a marker of cell polarity at confluence. From the total of 18 co-culture experiments performed, a subset of embryo attachment sites from 12 experiments was permeabilised and immunostained for MUC1. In a minority of the sites (16.9\%), loss of MUC1 was observed from both the epithelial cell surface and intracellular locations with a distinct boundary pattern to the attachment site (Fig. 3B-D and F), while an undisturbed mosaic pattern of MUC1 staining was observed away from the attachment site and also in control cells without co-cultured embryos (Fig. 3A). Figure $3 \mathrm{E}$ shows an example of a site from which little perceptible clearance has occurred. The percentage of embryos showing local MUC1 clearance was significantly different from the percentage of embryos reaching attachment 1 and attachment 2 stages $(P<0.001$ and $P<0.05$ respectively). The extent of MUC1 clearance from epithelial cells varied, with patches extending radially from $\sim 10-15$ cells to $\sim 60-70$ cells with patch diameter sometimes reaching $\sim 700 \mu \mathrm{m}$ (Fig. 3B-D).

\section{Zona pellucida removal increases stable embryo attachment but not local MUC1 clearance}

The proportion of embryos attaining initial attachment (attachment 1) from the assisted hatching group (93\%) was comparable with naturally hatching blastocysts (94\%; Table 1, row 6). However, significantly more embryos $(53 \%)$ attained stable attachment compared with naturally hatching blastocysts (33\%; Table 1 , rows 5 and 6 ).

A subset of assisted and naturally hatched embryo sites was stained with anti-MUC1 antibody. Despite the increase in stable attachment observed after assisted hatching, there was no significant difference in the local clearance of apical MUC1 (Table 1, rows 7 and 8).
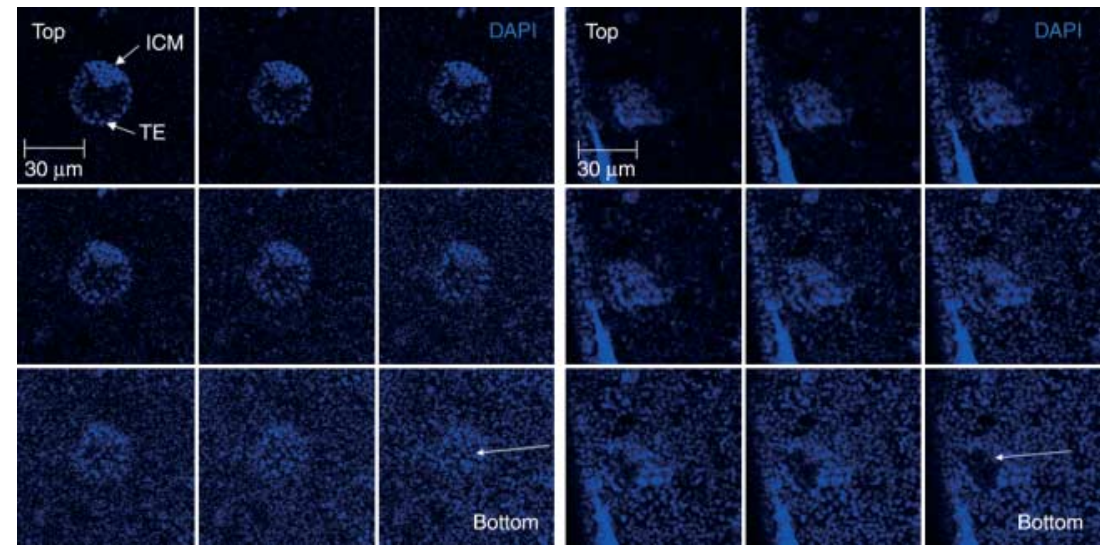

Figure 2 Two serial confocal sections of mouse blastocysts attached to Ishikawa cells. Each series runs from the upper $z$-plane at top left with only the blastocyst visible, to the bottom right lowest plane with clearly visible Ishikawa cell monolayer. In the left half of the figure, a blastocyst with clearly visible intact inner cell mass and trophectoderm is attached stably to the epithelial cell layer with minimum displacement or disruption of the underlying cells, marked by an arrow. In the series at right, a laterally spreading mouse embryo is attached stably with displacement of the underlying cells (arrow). At bottom left, the staining indicates uplift of the epithelial monolayer at the edge of the well. DAPI staining. 

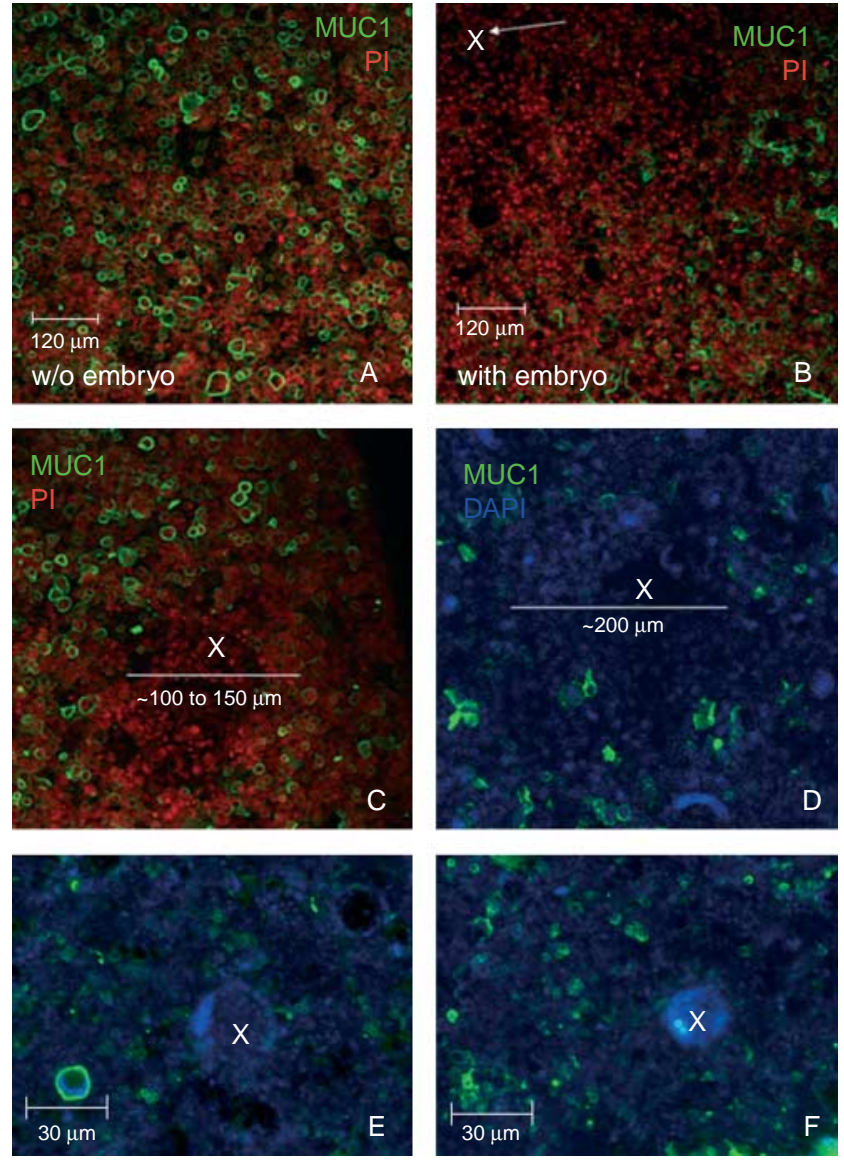

Figure 3 Surface features of Ishikawa cells in the presence of attached embryos. Indirect immunofluorescence staining for MUC1 with mAb BC2 in paraformaldehyde-fixed Ishikawa cell-embryo co-cultures. Counterstaining with propidium iodide (A-C) or 4',6-diamidino-2phenylindole (DAPI) (D-F). (A) Control culture with no embryos present. (B-D) Attachment sites with clearance of MUC1 (white bar). Note the variation in the diameter of cleared area. These embryos were displaced during processing, and the position of the attachment site is marked by ' $\mathrm{x}$ ' in the image. ( $\mathrm{E}, \mathrm{F})$ Embryos attached on an epithelial monolayer showing less (E) or more $(F)$ clearance of MUC1 beneath and immediately adjacent to the attached embryo. Normal MUC1 expression is observed away from the attachment site.

\section{Steroid hormone treatment of Ishikawa cells increases stable embryo attachment}

Expression of oestrogen receptor $\alpha$ (ER $\alpha$ or ESR1) mRNA in Ishikawa cells was confirmed by RT-qPCR, and progesterone treatment was observed to effect a radical reduction in ESR1 abundance (data not shown). Cells were grown in $17 \beta$-oestradiol $\left(\mathrm{OE}_{2}, 10^{-8} \mathrm{M}\right)$ for $24 \mathrm{~h}$, and were then switched to $\mathrm{OE}_{2}\left(10^{-8} \mathrm{M}\right)$ and medroxyprogesterone acetate (MPA, $\left.10^{-6} \mathrm{M}\right)$ for $24 \mathrm{~h}$. They were then co-cultured with embryos for a further $48 \mathrm{~h}$ in the presence of both steroids. After steroid incubation, increased immunoreactivity was observed for cell surface markers of the progesterone response, including MUC1, keratan sulphate and DBA-binding oligosaccharide (Fig. 4).
Results presented (in Table 1, rows 9-10) are the outcome of four independent experiments with similar number of embryos transferred in both steroid hormoneexposed and non-exposed Ishikawa cells. As shown, after $48 \mathrm{~h}$ of co-culture, no significant difference was observed between the two groups in initial attachment. However, a significant increase $(P<0.01)$ was observed in embryos reaching attachment 2 in steroid-treated cells compared with untreated cells.

Experiments $(N=2)$ were carried out attempting to define whether the effect of steroid was on the epithelial cells or on the embryos. Cells were exposed to $\mathrm{OE}_{2}$ for $24 \mathrm{~h}$, and then to $\mathrm{OE}_{2}$ and MPA for a further $24 \mathrm{~h}$. Finally, embryos $(n=18)$ were transferred for co-culture in a normal cell culture medium without steroid hormones. There was no significant difference in the percentage of embryos reaching attachment 1 and 2 compared with the control group, suggesting either that the steroid regimen affected both cells and blastocysts, or that a longer steroid hormone exposure may be required to create a more adhesive epithelium.

\section{Transferred embryos are competent to attach}

To confirm that blastocysts were viable and attachment competent, in each experiment embryos were incubated in a standard cell culture medium on tissue culture plastic for $48 \mathrm{~h}$. A high percentage of attachment was observed (90-95\%), and these sites were all stable to fixation. At $48 \mathrm{~h}$ after fixation, indirect immunofluorescence staining with placental lactogen-1 antibody ( $2 \mu \mathrm{g} / \mathrm{ml}$; Chemicon, Harrow, UK) was performed (not shown). Some embryos retained discernible inner cell mass and trophectoderm layer, while others were observed to be expanding laterally on the surface with loss of spherical shape and trophoblast spreading across the substrate (not shown).

\section{Expression of sialomucin on Ishikawa cells and secretory endometrium}

The sialomucin CD164, which emerged as a candidate adhesion molecule from an informatics screen of cell surface components in endometrium (Aplin \& Singh 2008, Singh \& Aplin 2009), is expressed in human secretory phase endometrium (d17 of the menstrual cycle) on luminal and glandular epithelial cells, where localisation was prominently apical, and also on the stromal cells (Fig. 5). Ishikawa cells stained homogeneously at the apical surface with antibody to CD164 (Fig. 6). Cell surface localisation was confirmed by flow cytometry of unpermeabilised cells (data not shown). The distribution of CD164 in Ishikawa cells with an attached embryo site was compared to control cells. A confocal $z$-series of a stably attached embryo (attachment 2) clearly indicates an intact inner cell 

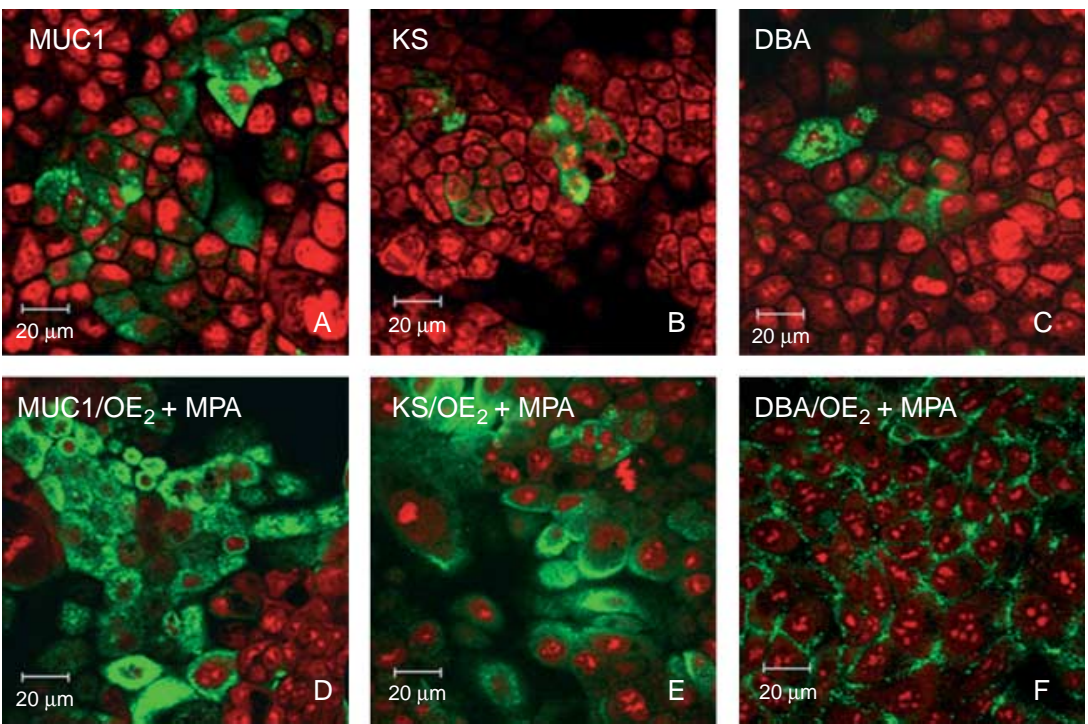

Figure 4 Immunofluorescence comparisons of Ishikawa cells treated with $\mathrm{OE}_{2}$ and MPA versus control untreated cells showing that the steroid regimen increases the expression of MUC1, keratan sulphate $(\mathrm{KS})$ and glycans recognised by the lectin DBA. Green, FITC-conjugated secondary antibody or streptavidin; red, PI. mass and trophectoderm layer and an undisturbed distribution of CD164 beneath and adjacent to the attachment site (Fig. 6). Control and embryo co-cultured Ishikawa cells showed similar homogeneous patterns of staining on the apical cell surface and in intracellular locations.

\section{Discussion}

Early morphological studies characterised the process of implantation as having three stages, apposition, attachment and invasion (Enders \& Schlafke 1969). Apposition has not been observed in vivo in humans (Hertig et al. 1959) or other primates (Enders 2000), probably because interactions between the embryo and epithelium are highly tenuous and embryos are lost during processing for histology. In mice, the uterus closes over the embryo to create an implantation chamber wherein apposition stages can be found by serial sectioning (Enders \& Schlafke 1969, Fouladi-Nashta et al. 2005). Here, the outer trophectodermal surface closely approaches the apical uterine epithelium. Attachment of human embryos has been examined on plastic-grown luminal epithelial cells (Meseguer et al. 2001) or endometrial biopsies (Bentin-Ley et al. 1999, Lalitkumar et al. 2007), but the scarcity of human embryos available for these studies means that only limited information could be obtained on the attachment reaction and statistical comparison of different conditions was not obtainable (Lindenberg et al. 1989, Bentin-Ley et al. 1999).

To study implantation in vitro, different types of endometrial and trophoblastic cells have been used, and they have provided valuable information (Hannan et al. 2009, Salamonsen et al. 2009), but our understanding of this process is still far from complete. The invasion phase has been effectively modelled using embryos adhering and expanding on endometrial stromal monolayers (Grewal et al. 2008), but this ignores the crucial initial phases of attachment and penetration of the epithelium. Human endometrial epithelial cells in primary culture show phenotypic abnormalities and loss of hormone response (Campbell et al. 1988, 2000). Ishikawa cells are stable in culture and have functional steroid hormone receptors. An increase in MUC1 in Ishikawa cells after steroid treatment correlates with previous data, indicating that progesterone regulates
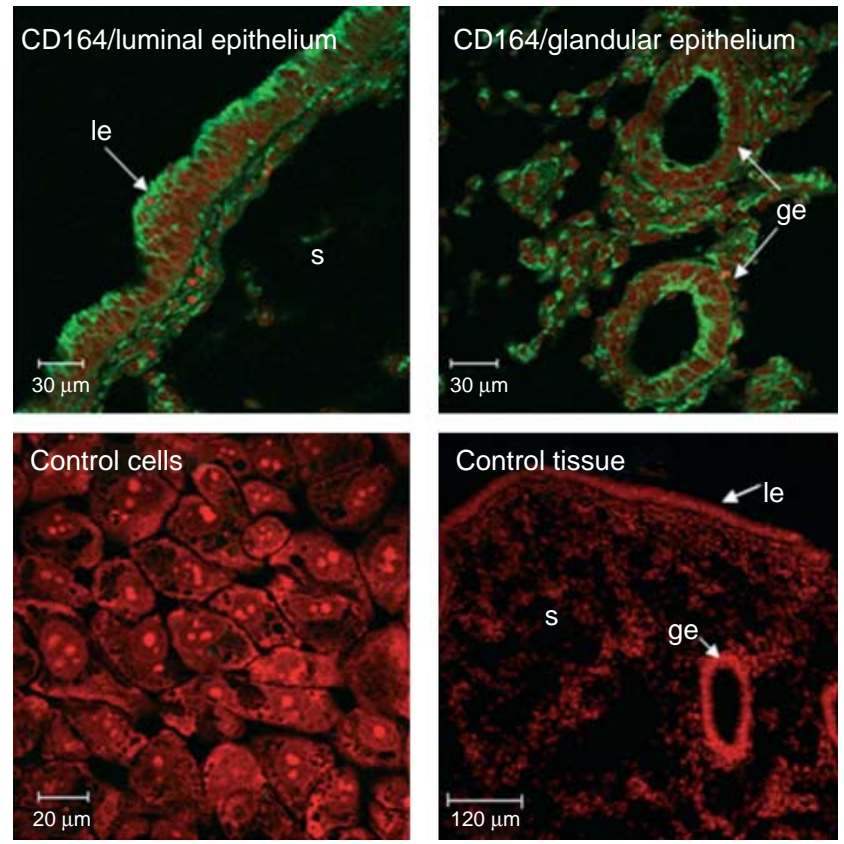

Figure 5 CD164 immunofluorescence. Top panels: endometrial biopsies during secretory phase showing strong CD164 staining on the luminal surface (le), glandular epithelial (ge) and stromal cells (s). Bottom panels: negative controls treated with isotype-matched primary antibodies show no staining of either Ishikawa cells (left) or tissue (right). 

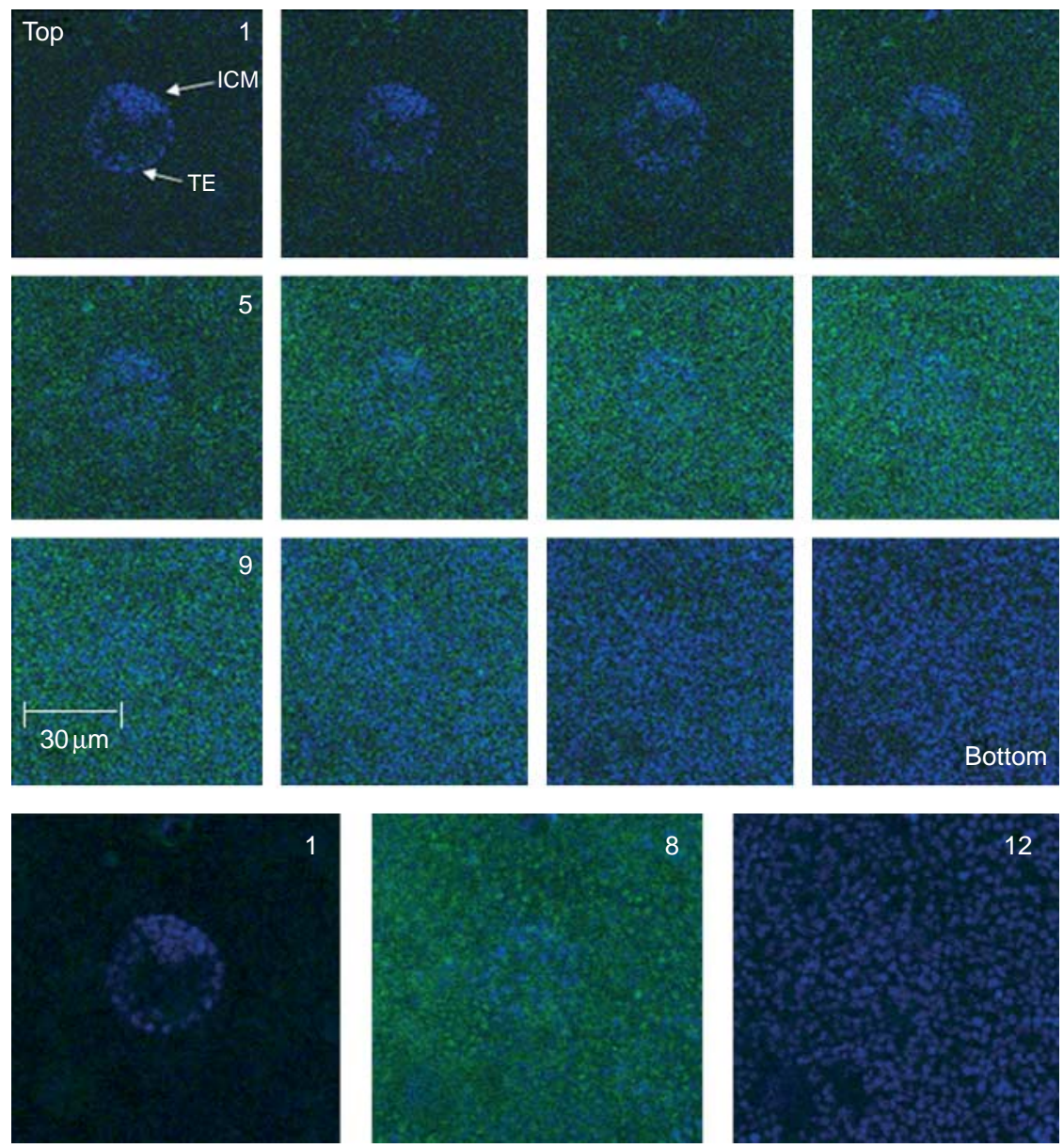

Figure 6 Confocal serial optical sections of an embryo attachment site stained for CD164.

The top left image in the montage is the upper plane view with only the blastocyst visible, while the bottom right is taken in a low plane with clearly visible Ishikawa cell monolayer. At the bottom are higher magnifications of images showing the embryo, apical Ishikawa cell and mid-Ishikawa planes. The stably attached blastocyst has an intact inner cell mass and trophectoderm. Apical CD164 is undisturbed adjacent to and beneath the embryo, and a homogeneous pattern of punctate staining is observed. Green, FITC-conjugated secondary antibody; blue, DAPI.
MUC1 expression in endometrial epithelial cells in vitro as well as in vivo (Kovarik et al. 1993). Combined oestrogen-progestin treatment also increases the expression of glycodelin A and the rate of attachment and adhesion of Jar cell spheroids (Uchida et al. 2007). Models that use choriocarcinoma cell spheroids are, however, limited by the absence of a well-polarised outer layer of trophectoderm and other phenotypic differences from normal trophoblast.

The present observations of mouse embryos attaching in vitro on human cells indicate an initial, clearly visible but highly tenuous interaction that is unstable to shear stresses introduced by medium change or fixation. Conceivably, this might be equated to the in vivo stage of apposition, which is reversible, allowing repositioning of the conceptus in the uterus. However, based on the nature of the observations made, we describe this as attachment 1 .

In the control experiments, essentially all embryos adhered and grew out on tissue culture plastic as described previously (Glass et al. 1980, Morris et al. 1983). Mouse embryos also attach efficiently in vitro to mouse luminal epithelial cells (unpublished data). Consistent with this, a large majority of the embryos transferred to human Ishikawa cell monolayers were found to be competent to undergo attachment within $48 \mathrm{~h}$ of transfer. These findings suggest that attachment 1 is a phase in which components of the apical glycocalyx may mediate weak binding to receptors on trophectoderm (Aplin 2000, Kimber \& Spanswick 2000). Less than half of the transferred embryos progressed from this stage to stable (shear stress-resistant) attachment, a figure that echoes the high rates of implantation failure in ART programmes (de los Santos et al. 2003, Kovalevsky \& Patrizio 2005). Staining at this stage with antibody to the apical glycoprotein CD164 showed no perceptible disturbance to distribution, indicating that interaction with the embryo may not yet have triggered a major reorganisation of the glycocalyx. Given the evident viability of the embryos used in the present study, the data confirm that receptivity is vested in the endometrial epithelial lining, which has the capacity to act as a barrier to the implanting blastocyst (Aplin 2006).

Our data are consistent with previous observations that Ishikawa cells express ESR1. Progesterone downregulates ESR1 mRNA in Ishikawa cells and similarly during the mid-secretory phase of the menstrual cycle when LE cells are receptive (Lessey et al. 1988). 
In vitro, stable attachment increased more than 1.7-fold on steroid-treated cells, adding evidence in support of the fidelity of this model of embryo-epithelial interaction. A similar increase in surface receptivity in mouse uterine cell monolayers after hormone treatment in vitro has been reported (Lavranos \& Seamark 1989). Withdrawal of steroid prior to embryo co-culture reduced the percentage of embryos reaching stable attachment to the control level, so that the increase in attachment in steroid-treated cells could have been due to either an activating effect of steroids on the blastocyst (Paria et al. 1998) or the fact that epithelial cells need longer incubation with progestin to become receptive. Thus, it is not possible to ascertain whether the increase in stable attachment is due to hormone effects on Ishikawa cells or a dual effect on both cells and blastocysts. However, indirect immunofluorescence indicated increases in P-dependent markers including DBA-binding sugars, MUC1 and associated keratan sulphate on Ishikawa cells after steroid treatment. Experiments in steroid-stripped culture medium in various exogenous steroid regimens are now required in order to determine the mechanism of hormone action in this system, and it will be important to investigate any influence on MUC1 clearance that might in turn impact on stable embryo attachment.

Surprisingly, Ishikawa cells grown on glass do not support blastocyst attachment. This result suggests a connection between basal adhesion substrate and apical phenotype, emphasising the possibility that basement membrane may alter polarity and, in turn, receptivity in vivo.

In mouse embryo-Ishikawa cell co-cultures, the embryo induces clearance of MUC1 at its attachment site as observed previously in human embryo/human primary epithelial cell system (Meseguer et al. 2001). CD164 (Singh \& Aplin 2009) acted as a control in these experiments: it is apically distributed and appears undisturbed at sites of stable attachment. Ishikawa cells express MUC1 as a mosaic, whereas mid-secretory luminal epithelial cells in vivo show continuous apical immunoreactivity. Despite this limitation, it was readily apparent that cells both beneath and immediately adjacent to attached embryos lacked detectable MUC1, creating a boundary effect of variable diameter, with cells further away in the epithelial layer remaining unaffected. Not all transferred or attaching embryos caused local MUC1 clearance; it is not clear whether this reflects attachment at a later time of co-culture, with clearance following after a delay, or whether there may be intrinsic variations in embryo potency. Thus, although mouse embryos are not normally required to effect clearance in vivo since MUC1 is downregulated under maternal control (Surveyor et al. 1995), at least some of them retain the ability to do so. Local downregulation of MUC1 is also observed in rabbit implantation chambers (Hoffman et al. 1998), and has been postulated to be required in humans (Meseguer et al. 2001).
Zona pellucida removal by assisted hatching prior to co-culture increased stable attachment of embryos, indicating a possible effect on embryo activation. The lack of an effect on clearance rates shows that removal of MUC1 is mechanistically independent from stable attachment. However, the present observations indicate that MUC1 clearance is not a prerequisite for stable attachment. Thus, the data are consistent with a dual role of MUC1 as initial docking site and barrier to further advancement of the adhesion cascade (Aplin \& Kimber 2004, Aplin 2006) with the involvement of other, higher affinity adhesion systems. Although the current study does not address the nature of embryoderived signals, removal of mucin appears to be accomplished by direct action of the blastocyst rather than in response to ovarian steroid. There is a possibility of localised cleavage of the extracellular domain of the mucin, because trophoblast in the implanting blastocyst is known to elaborate several proteases (Thathiah et al. 2003, Thathiah \& Carson 2004), or that short-range soluble signals pass locally between the embryo and maternal cells (Dominguez et al. 2002, Cameo et al. 2004, Cervero et al. 2005).

After the apposition and adhesion phases, there follows displacement/disruption and eventual invasion. Access of the trophectoderm to the lateral epithelial surface is a crucial early step in both humans and rodents (Parr et al. 1987, Pampfer \& Donnay 1999, Lopata et al. 2002). In the apposition phase, the presence of a human blastocyst protects epithelial cells against the apoptotic/displacement pathway, while after adhesion it induces apoptosis (Galan et al. 2000). After the mouse blastocyst adheres to the Ishikawa cell monolayer, it similarly appears to induce a displacement reaction in cells in close contact, as is the nature of mouse blastocyst implantation. Further work will be required to define the mechanism, which may involve apoptosis.

Though caution is required in extrapolating from data obtained in a model that uses mouse embryos interacting with human cells, the observations reported here are useful in the formulation of hypotheses regarding early implantation events in humans in vivo. Our data suggest that most mouse embryos are capable of initiating a dialogue with human uterine epithelium, but that this process is often stalled, as indicated by failure to reach stable attachment within a normal time frame, failure to remodel surface epithelial composition or failure to advance to the stage of epithelial displacement. Previously, the suggestion was made that poor-quality embryos might fail at the epithelial 'barrier' phase of implantation (Aplin 1996, 1997). Based on the observation of distinct phases in embryo-epithelial interaction, a hypothesis has been suggested that low-quality embryos undergo initial attachment, but lack the ability to clear MUC1 or advance to stable adhesion or displacement. The model 
offers the possibility to dissect molecular mechanisms in embryo attachment, and has the potential to throw new light on implantation and its failure.

\section{Materials and Methods}

\section{Animals and superovulation protocol}

All work was conducted and licensed under the Animal Act, 1986, and had local ethical approval. CD1 strain of males and MF1 female mice (wild-type outbred; Harlan Olac Ltd, Bicester, UK) were used. Unless otherwise stated, males were caged singly and were $<6$ months old. All mice were kept under standard environmental conditions of $12 \mathrm{~h}$ light: $12 \mathrm{~h}$ darkness, controlled room temperature $\left(20-22{ }^{\circ} \mathrm{C}\right.$ and $40-60 \%$ humidity) with food and water provided ad libitum.

Female mice were superovulated with $5 \mathrm{IU}$ of pregnant mare serum gonadotrophin (Calbiochem, Nottingham, UK) administered as a $0.1-\mathrm{ml} \mathrm{i.p.} \mathrm{injection.} \mathrm{Ovulation} \mathrm{was} \mathrm{synchronised} \mathrm{by} \mathrm{a}$ $0.1-\mathrm{ml}$ i.p. injection of $5 \mathrm{IU}$ human chorionic gonadotrophin (hCG, Intervet UK Ltd, Milton Keynes, UK) 46-48 h later. Females were then placed singly with males of the same strain overnight. The presence of a vaginal plug the following morning (day 1 of pregnancy) was used as an indicator of successful mating.

\section{Retrieval of blastocysts from mouse uteri}

Mice at day 4 of pregnancy were killed $94-96 \mathrm{~h}$ post hCG administration by cervical dislocation. The uterine horns were dissected, fat was removed and horns were placed directly in flushing medium - Ham's F-10 (Gibco) + 0.4\% BSA (Sigma), and ovaries were checked to confirm the presence of corpora lutea. Embryos were flushed from uterine horns using a 28-G sterile hypodermic needle and $1-\mathrm{ml}$ syringe. Predominantly, blastocysts were recovered along with some arrested morulae and fragmented embryos. Embryos were washed through $3 \times 60 \mu \mathrm{l}$ drops of flushing medium followed by two washes in DMEM cell culture medium (Biowhittaker, Cambrex Corp., Cambridge, UK).

For assisted hatching, acidic Tyrode's solution was used. A set of experiments was carried out to examine the effect of zona pellucida removal on embryo attachment prior to co-culturing with Ishikawa cells. Approximately $40 \%$ of the blastocysts recovered per experiment were transferred to a $60-\mu \mathrm{l}$ drop of acidic Tyrode's solution ( $\mathrm{pH}$ 2.3) for $1 \mathrm{~min}$. The resulting zonafree blastocysts were washed in embryo flushing medium $(\times 6)$ and in DMEM cell culture medium $(\times 3)$.

\section{Cell culture and transfer of blastocysts to Ishikawa cell monolayers}

Ishikawa cells were maintained in DMEM containing $20 \mathrm{mM}$ Hepes (Cambrex) and 10\% foetal bovine serum (Gibco) and $1 \mathrm{mM}$ sodium pyruvate (Sigma). In addition to these, the medium was supplemented with antibiotics - $2 \mathrm{mM}$ L-glutamine, $100 \mu \mathrm{g} / \mathrm{ml}$ streptomycin and $100 \mathrm{IU} / \mathrm{ml}$ penicillin. Cells were grown in microwell plates (Corning Costar, Corning
Ltd, Sunderland, UK) in an atmosphere of 95\% air and 5\% $\mathrm{CO}_{2}$. In an attempt to carry out optimal high resolution light microscopic morphological studies, Ishikawa cells were grown on culture-grade glass chamber well slides (Nunc Lab-Tek II, Nalge Ltd, Hereford, UK).

\section{Attachment on Ishikawa cells}

Once collected in a final drop of DMEM, embryos were transferred unselectively to confluent Ishikawa cell monolayers grown in a 96-well plate. Between 1 and 5 blastocysts were transferred per well depending upon the total number recovered. Co-cultures were incubated undisturbed at $37^{\circ} \mathrm{C}$ in a $5 \% \mathrm{CO}_{2}$ humidified chamber for $48 \mathrm{~h}$, and were then fixed at $48 \mathrm{~h}$ in $8 \%$ paraformaldehyde (BDH, Poole, UK) in PBS for $30 \mathrm{~min}$ at room temperature. Embryo locations were noted before and after fixation. Embryos attached before fixation were defined as having reached attachment 1 , while those that remained attached after gentle fixation were defined as having reached attachment 2 .

\section{Indirect immunofluorescence}

Mid-secretory endometrium was collected with permission from the local ethics committee, snap-frozen and cryosectioned for staining. Fixed attached embryos on epithelial cell monolayers were washed twice in PBS, and (where specified) the cells were permeabilised for $15 \mathrm{~min}$ in PBS containing $0.5 \%$ Triton X-100 (Sigma). All incubations and washes were carried out at room temperature. The cells were rinsed with PBS $(3 \times 5 \mathrm{~min})$, incubated with a primary antibody (anti-MUC1 clone BC2, mouse $\operatorname{lgG}, 0.5 \mu \mathrm{g} / \mathrm{ml}$, anti-keratan sulphate 5D4, mouse IgG, $0.5 \mu \mathrm{g} / \mathrm{ml}$ or anti-CD164 clone N6B6, mouse IgG, $2.5 \mu \mathrm{g} / \mathrm{ml}$; BD Biosciences, Oxford, UK) for $2 \mathrm{~h}$, washed in PBS for $3 \times 5 \mathrm{~min}$, and then incubated with 1:50 polyclonal rabbit anti-mouse FITC-conjugated secondary antibody (DakoCytomation Ltd, Cambridge, UK) for $1 \mathrm{~h}$ in darkness. Antibodies to human MUC1 and CD164 did not cross-react with mice. The cells were incubated with DBA (Sigma; $10 \mu \mathrm{g} / \mathrm{ml}$ ), followed by incubation with FITC-streptavidin. The cells were rinsed with PBS $(3 \times 5 \mathrm{~min})$, and the nuclei were stained with $2 \mu \mathrm{M}$ propidium iodide (Sigma) or 4',6-diamidino-2-phenylindole dilactate (Sigma) for $10 \mathrm{~min}$. Finally, the cells were rinsed with PBS $(3 \times 5 \mathrm{~min})$, and the wells were filled with PBS containing anti-fade 1,4-diazabicyclo[2.2.2] octane (Sigma), wrapped in an aluminium foil and stored at $4{ }^{\circ} \mathrm{C}$. Images were captured under phase contrast (Nikon Eclipse TE 300), epifluorescence or laser scanning confocal microscopy using Kalman optics (Olympus microscope connected to a laser scanning attachment (Bio-Rad) and also a Leica SP2 confocal microscope). Z-series optical sections were obtained at $1-\mu \mathrm{m}$ increments. The laser scan head was operated by standard Zeiss and Bio-Rad software. As a control for non-specific staining by the secondary antibody, staining was performed with omission of the primary antibody or with a negative control antibody of the same isotype (DakoCytomation Ltd, Cambridge, UK). Cells without transferred embryos were also used as controls. Controls (both cultures and tissue sections) were uniformly negative. 


\section{Statistical analysis}

Blastocysts cultured on Ishikawa cells, culture-grade plastic or culture-grade glass were scored for attachment prior to and after fixation, representing attachment 1 and attachment 2 respectively. Changes induced in the apical glycocalyx in response to attachment were also assessed. Results for overall attachment and MUC1 clearance by naturally and assisted hatched embryos were analysed statistically. Statistical significance $(P<0.05)$ was tested using Student's $t$-test and one-way ANOVA. Normalisation was achieved by taking the arcsine of the square root of the proportion before analysis. Data shown in Table 1 were arrived at by aggregating the means of several experiments in which the total numbers of embryos varied. When data were reanalysed after aggregating the total embryos used (each embryo as a data point), statistically significant differences were conserved in all cases.

\section{Declaration of interest}

The authors declare that there is no conflict of interest that could be perceived as prejudicing the impartiality of the research reported.

\section{Funding}

We are grateful to Ardana Bioscience for partial studentship support to $\mathrm{H}$ Singh.

\section{References}

Aplin JD 1991 Glycans as biochemical markers of human endometrial secretory differentiation. Journal of Reproduction and Fertility 92 525-541.

Aplin JD 1996 The cell biology of human implantation. Placenta 17 269-275.

Aplin JD 1997 Adhesion molecules in implantation. Reviews of Reproduction 2 84-93.

Aplin JD 2000 The cell biological basis of human implantation. Baillieres Best Practice \& Research. Clinical Obstetrics \& Gynaecology 14 757-764.

Aplin JD 2006 Embryo implantation: the molecular mechanism remains elusive. Reproductive Biomedicine Online 13 833-839.

Aplin JD \& Kimber SJ 2004 Trophoblast-uterine interactions at implantation. Reproductive Biology and Endocrinology 248.

Aplin JD \& Singh H 2008 Bioinformatics and transcriptomics studies of early implantation. Annals of the New York Academy of Sciences 1127 116-120.

Aplin JD, Hey NA \& Li TC 1996 MUC1 as a cell surface and secretory component of endometrial epithelium: reduced levels in recurrent miscarriage. American Journal of Reproductive Immunology $\mathbf{3 5}$ 261-266.

Aplin JD, Jones CJ, McGinlay PB, Croxatto HB \& Fazleabas AT 1997 Progesterone regulates glycosylation in endometrium. Biochemical Society Transactions 25 1184-1187.

Aplin JD, Hey NA \& Graham RA 1998 Human endometrial MUC1 carries keratan sulfate: characteristic glycoforms in the luminal epithelium at receptivity. Glycobiology 8 269-276.

Bentin-Ley U, Sjogren A, Nilsson L, Hamberger L, Larsen JF \& Horn T 1999 Presence of uterine pinopodes at the embryo-endometrial interface during human implantation in vitro. Human Reproduction 14 515-520.

Bergh PA \& Navot D 1992 The impact of embryonic development and endometrial maturity on the timing of implantation. Fertility and Sterility 58 537-542.
Cameo P, Srisuparp S, Strakova Z \& Fazleabas AT 2004 Chorionic gonadotropin and uterine dialogue in the primate. Reproductive Biology and Endocrinology 250.

Campbell S, Seif MW, Aplin JD, Richmond SJ, Haynes P \& Allen TD 1988 Expression of a secretory product by microvillous and ciliated cells of the human endometrial epithelium in vivo and in vitro. Human Reproduction 3 927-934.

Campbell S, Larsen J, Seif MW, Allen TD, Knox F, Jones CJ \& Aplin JD 2000 Mosaic characteristics of human endometrial epithelium in vitro: analysis of secretory markers and cell surface ultrastructure. Molecular Human Reproduction 6 41-49.

Castelbaum AJ, Ying L, Somkuti SG, Sun J, Ilesanmi AO \& Lessey BA 1997 Characterization of integrin expression in a well differentiated endometrial adenocarcinoma cell line (Ishikawa). Journal of Clinical Endocrinology and Metabolism 82 136-142.

Cervero A, Horcajadas JA, Dominguez F, Pellicer A \& Simon C 2005 Leptin system in embryo development and implantation: a protein in search of a function. Reproductive Biomedicine Online 10 217-223.

Devine PL \& McKenzie IF 1992 Mucins: structure, function, and associations with malignancy. BioEssays 14 619-625.

Dominguez F, Pellicer A \& Simon C 2002 Paracrine dialogue in implantation. Molecular and Cellular Endocrinology 186 175-181.

Enders AC 2000 Trophoblast-uterine interactions in the first days of implantation: models for the study of implantation events in the human. Seminars in Reproductive Medicine 18 255-263.

Enders AC \& Schlafke S 1969 Cytological aspects of trophoblast-uterine interaction in early implantation. American Journal of Anatomy 125 $1-29$.

Fouladi-Nashta AA, Jones CJ, Nijjar N, Mohamet L, Smith A, Chambers I \& Kimber SJ 2005 Characterization of the uterine phenotype during the peri-implantation period for LIF-null, MF1 strain mice. Developmental Biology 281 1-21.

Galan A, O'Connor JE, Valbuena D, Herrer R, Remohi J, Pampfer S, Pellicer A \& Simon C 2000 The human blastocyst regulates endometrial epithelial apoptosis in embryonic adhesion. Biology of Reproduction 63 430-439.

Genbacev OD, Prakobphol A, Foulk RA, Krtolica AR, Ilic D, Singer MS, Yang ZQ, Kiessling LL, Rosen SD \& Fisher SJ 2003 Trophoblast L-selectin-mediated adhesion at the maternal-fetal interface. Science 299 405-408.

Glass RH, Spindle Al, Maglio M \& Pedersen RA 1980 The free surface of mouse trophoblast in culture is non-adhesive for other cells. Journal of Reproduction and Fertility 59 403-407.

Grewal S, Carver JG, Ridley AJ \& Mardon HJ 2008 Implantation of the human embryo requires Rac1-dependent endometrial stromal cell migration. PNAS 105 16189-16194.

Hannan NJ, Paiva P, Dimitriadis E \& Salamonsen LA 2009 Models for study of human embryo implantation: choice of cell lines? Biology of Reproduction 82 235-245.

Hata H \& Kuramoto H 1992 Immunocytochemical determination of estrogen and progesterone receptors in human endometrial adenocarcinoma cells (Ishikawa cells). Journal of Steroid Biochemistry and Molecular Biology 42 201-210.

Heneweer C, Schmidt M, Denker HW \& Thie M 2005 Molecular mechanisms in uterine epithelium during trophoblast binding: the role of small GTPase RhoA in human uterine Ishikawa cells. Journal of Experimental \& Clinical Assisted Reproduction 24.

Hertig AT, Rock J, Adams EC \& Menkin MC 1959 Thirty-four fertilized human ova, good, bad and indifferent, recovered from 210 women of known fertility; a study of biologic wastage in early human pregnancy. Pediatrics 23 202-211.

Hey NA \& Aplin JD 1996 Sialyl-Lewis x and Sialyl-Lewis a are associated with MUC1 in human endometrium. Glycoconjugate Journal 13 769-779.

Hey NA, Graham RA, Seif MW \& Aplin JD 1994 The polymorphic epithelial mucin MUC1 in human endometrium is regulated with maximal expression in the implantation phase. Journal of Clinical Endocrinology and Metabolism 78 337-342.

Hey NA, Li TC, Devine PL, Graham RA, Saravelos H \& Aplin JD 1995 MUC1 in secretory phase endometrium: expression in precisely dated biopsies and flushings from normal and recurrent miscarriage patients. Human Reproduction 10 2655-2662. 
Hilkens J, Ligtenberg MJ, Vos HL \& Litvinov SV 1992 Cell membraneassociated mucins and their adhesion-modulating property. Trends in Biochemical Sciences 17 359-363.

Hoadley ME, Seif MW \& Aplin JD 1990 Menstrual-cycle-dependent expression of keratan sulphate in human endometrium. Biochemical Journal 266 757-763.

Hoffman LH, Olson GE, Carson DD \& Chilton BS 1998 Progesterone and implanting blastocysts regulate Muc1 expression in rabbit uterine epithelium. Endocrinology 139 266-271.

Hohn HP, Linke M \& Denker HW 2000 Adhesion of trophoblast to uterine epithelium as related to the state of trophoblast differentiation: in vitro studies using cell lines. Molecular Reproduction and Development $\mathbf{5 7}$ 135-145.

Horne AW, Lalani EN, Margara RA, Ryder TA, Mobberley MA \& White JO 2005 The expression pattern of MUC1 glycoforms and other biomarkers of endometrial receptivity in fertile and infertile women. Molecular Reproduction and Development 72 216-229.

Jones CJ, Fazleabas AT, McGinlay PB \& Aplin JD 1998 Cyclic modulation of epithelial glycosylation in human and baboon (Papio anubis) endometrium demonstrated by the binding of the agglutinin from Dolichos biflorus. Biology of Reproduction 58 20-27.

Kimber SJ \& Spanswick C 2000 Blastocyst implantation: the adhesion cascade. Seminars in Cell and Developmental Biology 11 77-92.

Kovalevsky G \& Patrizio P 2005 High rates of embryo wastage with use of assisted reproductive technology: a look at the trends between 1995 and 2001 in the United States. Fertility and Sterility 84 325-330.

Kovarik A, Peat N, Wilson D, Gendler SJ \& Taylor-Papadimitriou J 1993 Analysis of the tissue-specific promoter of the MUC1 gene. Journal of Biological Chemistry $2689917-9926$.

Lagow E, DeSouza MM \& Carson DD 1999 Mammalian reproductive tract mucins. Human Reproduction Update 5 280-292.

Lalitkumar PG, Lalitkumar S, Meng CX, Stavreus-Evers A, Hambiliki F, Bentin-Ley U \& Gemzell-Danielsson K 2007 Mifepristone, but not levonogestrel, inhibits human blastocyst attachment to an in vitro endometrial three-dimensional cell culture model. Human Reproduction 22 3031-3037.

Lavranos TC \& Seamark RF 1989 Addition of steroids to embryo-uterine monolayer co-culture enhances embryo survival and implantation in vitro. Reproduction, Fertility, and Development 1 41-46.

Lessey BA 2002 Adhesion molecules and implantation. Journal of Reproductive Immunology 55 101-112.

Lessey BA, Killam AP, Metzger DA, Haney AF, Greene GL \& McCarty KS Jr 1988 Immunohistochemical analysis of human uterine estrogen and progesterone receptors throughout the menstrual cycle. Journal of Clinical Endocrinology and Metabolism 67 334-340.

Lessey BA, Ilesanmi AO, Castelbaum AJ, Yuan L, Somkuti SG, Chwalisz K \& Satyaswaroop PG 1996 Characterization of the functional progesterone receptor in an endometrial adenocarcinoma cell line (Ishikawa): progesterone-induced expression of the alpha1 integrin. Journal of Steroid Biochemistry and Molecular Biology 59 31-39.

Ligtenberg MJ, Buijs F, Vos HL \& Hilkens J 1992 Suppression of cellular aggregation by high levels of episialin. Cancer Research 52 2318-2324.

Lindenberg S, Hyttel P, Sjogren A \& Greve T 1989 A comparative study of attachment of human, bovine and mouse blastocysts to uterine epithelial monolayer. Human Reproduction 4 446-456.

Lopata A 1996 Blastocyst-endometrial interaction: an appraisal of some old and new ideas. Molecular Human Reproduction 2 519-525.

Lopata A, Bentin-Ley U \& Enders A 2002 "Pinopodes" and implantation. Reviews in Endocrine and Metabolic Disorders 3 77-86.

Meseguer M, Aplin JD, Caballero-Campo P, O'Connor JE, Martin JC, Remohi J, Pellicer A \& Simon C 2001 Human endometrial mucin MUC1 is up-regulated by progesterone and down-regulated in vitro by the human blastocyst. Biology of Reproduction 64 590-601.

Mo B, Vendrov AE, Palomino WA, DuPont BR, Apparao KB \& Lessey BA 2006 ECC-1 cells: a well-differentiated steroid-responsive endometrial cell line with characteristics of luminal epithelium. Biology of Reproduction 75 387-394.
Morris JE, Potter SW, Rynd LS \& Buckley PM 1983 Adhesion of mouse blastocysts to uterine epithelium in culture: a requirement for mutual surface interactions. Journal of Experimental Zoology $\mathbf{2 2 5}$ 467-479.

Nishida M, Kasahara K, Kaneko M, Iwasaki H \& Hayashi K 1985 Establishment of a new human endometrial adenocarcinoma cell line, Ishikawa cells, containing estrogen and progesterone receptors. Nippon Sanka Fujinka Gakkai Zasshi 37 1103-1111.

Pampfer S \& Donnay I 1999 Apoptosis at the time of embryo implantation in mouse and rat. Cell Death and Differentiation 6 533-545.

Paria BC, Das SK \& Dey SK 1998 Embryo implantation requires estrogendirected uterine preparation and catecholestrogen-mediated embyronic activation. Advances in Pharmacology 42 840-843.

Parr EL, Tung HN \& Parr MB 1987 Apoptosis as the mode of uterine epithelial cell death during embryo implantation in mice and rats. Biology of Reproduction 36 211-225.

Psychoyos A 1986 Uterine receptivity for nidation. Annals of the New York Academy of Sciences 476 36-42.

Salamonsen LA, Nie G, Hannan NJ \& Dimitriadis E 2009 Society for Reproductive Biology Founders' Lecture 2009. Preparing fertile soil: the importance of endometrial receptivity. Reproduction, Fertility, and Development 21 923-934.

de los Santos MJ, Mercader A, Galan A, Albert C, Romero JL \& Pellicer A 2003 Implantation rates after two, three, or five days of embryo culture. Placenta 24 (Supplement B) S13-S19.

Singh H \& Aplin JD 2009 Adhesion molecules in endometrial epithelium: tissue integrity and embryo implantation. Journal of Anatomy $\mathbf{2 1 5}$ $3-13$.

Somkuti SG, Yuan L, Fritz MA \& Lessey BA 1997 Epidermal growth factor and sex steroids dynamically regulate a marker of endometrial receptivity in Ishikawa cells. Journal of Clinical Endocrinology and Metabolism 82 2192-2197.

Surveyor GA, Gendler SJ, Pemberton L, Das SK, Chakraborty I, Julian J, Pimental RA, Wegner CC, Dey SK \& Carson DD 1995 Expression and steroid hormonal control of Muc-1 in the mouse uterus. Endocrinology 136 3639-3647.

Sutherland AE, Calarco PG \& Damsky CH 1993 Developmental regulation of integrin expression at the time of implantation in the mouse embryo. Development 119 1175-1186.

Thathiah A \& Carson DD 2004 MT1-MMP mediates MUC1 shedding independent of TACE/ADAM17. Biochemical Journal 382 363-373.

Thathiah A, Blobel CP \& Carson DD 2003 Tumor necrosis factor-alpha converting enzyme/ADAM 17 mediates MUC1 shedding. Journal of Biological Chemistry 278 3386-3394.

Uchida H, Maruyama T, Ohta K, Ono M, Arase T, Kagami M, Oda H, Kajitani T, Asada H \& Yoshimura Y 2007 Histone deacetylase inhibitorinduced glycodelin enhances the initial step of implantation. Human Reproduction 22 2615-2622.

Wesseling J, van der Valk SW \& Hilkens J 1996 A mechanism for inhibition of E-cadherin-mediated cell-cell adhesion by the membrane-associated mucin episialin/MUC1. Molecular Biology of the Cell 7 565-577.

Widra EA, Weeraratna A, Stepp MA, Stillman RJ \& Patierno SR 1997 Modulation of implantation-associated integrin expression but not uteroglobin by steroid hormones in an endometrial cell line. Molecular Human Reproduction 3 563-568.

Yoshinaga K 1988 Uterine receptivity for blastocyst implantation. Annals of the New York Academy of Sciences 541 424-431.

Received 1 July 2009

First decision 18 August 2009

Revised manuscript received 25 January 2010

Accepted 23 February 2010 